\title{
EDITORIAL
}

\section{CLIMATE CHANGE: IMPACT ON HEALTH}

From time immemorial human activities have changed the face of earth irreversibly. Of all the components of the ecosystems, climate change will be the most visibly affected and felt across the world due to these human actions. The fine balance between human need and sustainability of environment has long been disrupted. The end-result of this is degradation of human health which hinges on inter-play between human and nature. Pro-active measures will be needed to counter the adverse effects of climate change on human health and health professionals are strategically placed to do this job.

Human health is directly and indirectly affected by climate change. The venerable Lancet and University College London Institute for Global Health Commission have recently published a comprehensive report on health effects of climate change. ${ }^{1}$ The Commission found that rapid changes of weather pattern with rising number of extreme weather events are affecting health of the vulnerable population directly. Changes in agriculture, human habitat, availability of clean water can lead to worsening health status indirectly. Evidence have accumulated that climate change has induced impacts on human health that can be divided in three broad categories -alternation in distribution of disease vectors, change in seasonality of allergenic pollen species, rise of heat-related deaths. ${ }^{2}$

Global climate change will affect different regions of the world in different proportion. It is estimated that adverse health effects are likely to be more profound in developing countries like Bangladesh. ${ }^{3}$ With its large population, Bangladesh is at the fore-front of climate calamity related health effects. At-risk population includes children and the elderly, urban poor, traditional societies, coastal population. The World Health Organization estimates that 25\% of global disease burden including more than one-third of children is related to environmental factors. The mortality rate is higher in developing countries (25\%) compared with developed (17\%) countries. ${ }^{4}$

Studies indicate that climate change will increase the burden of diarrheal disease in South Asia including Bangladesh. ${ }^{2}$ Diarrhea related death is set to increase particularly during flood and droughts. Heavy rainfall results in overflow of sewerage and latrines, thereby increasing rates of diarrheal illness. The other end of the spectrum also holds true. Scarcity of water directly impacts on personal hygiene and food hygiene. This has the potential to contaminate water treatment plants as well. High temperature is an independent risk factor for increased occurrence of cholera and salmonella outbreak. Cholera outbreak in coastal region of Bangladesh has been linked to increased sea surface temperature and abundance of plankton. This plankton is thought to be the environmental reservoir for cholera. ${ }^{5}$ It is estimated that climate change will cause $10 \%$ extra deaths on top of 2.2 million deaths annually due to diarrheal diseases by $2030 .^{6}$

The geographical and seasonal distribution of vectorborne diseases like malaria, dengue are changing. Dengue, for example, is now widely prevalent in major cities in Bangladesh where it has established a strong presence. ${ }^{2}$ These diseases are dependent on temperature, rainfall, urbanization, socioeconomic status, population migration among others which in turn are dependent on climate conditions. Increased replication and transmissibility of pathogens are thought to be behind frequent outbreak of infectious diseases. Breeding sites of mosquito usually increase after a flood and incidence of malaria usually parallels this pattern. Warmer temperature helps increase vector breeding and reduces the organism's maturation time within the vector. Similarly, rodent-borne diseases like leptospirosis show an upward trend following a flood event. ${ }^{5}$ Health systems of affected countries like Bangladesh need to address this changing pattern of infectious diseases by adopting better vector control program, case detection, reporting and appropriate treatment by adhering to local guidelines. Better surveillance systems with international collaboration will help to determine the changing needs of vulnerable population.

Of particular concern is the changing pattern of rainfall during the rainy season. The traditional rainy season is showing a shifting trend from June-July to late August or September. ${ }^{7}$ This change in precipitation pattern could have implications in fresh water availability, water-logging, agriculture, food security. All of these are likely to contribute to the development of water-borne diseases, skin diseases, eye diseases, malnutrition and infectious diseases like dengue. 
Climate change is likely to increase the average temperature of the summer season with frequent and prolonged heat waves. In recent years there is an upward trend of temperature especially during the summer season. The fallout of these heat waves are heat stroke, dehydration, cardiovascular morbidity. ${ }^{5}$ In South Asia, heat waves have caused deaths among the vulnerable groups like day laborers and elderly. Hot working environment also increases probability of non-fatal accidents. Physical as well as mental ability to perform diminishes in this condition resulting in reduced productivity. Urban areas suffer from 'heat island' effect where the average temperature is higher than other areas. ${ }^{5}$ Although there is no large-scale study in Bangladesh to assess the impact of extreme heat-related events, it can be assumed that there will be more heat-related morbidity and mortality in the days to come. Records also indicate that diarrheal diseases increase during heat waves particularly in children in Bangladesh. Collaboration between the health sector and other sectors can help to safeguard the vulnerable from extreme heat events both at home and at work.

Rising sea level is a threat to the coastal population in Bangladesh. Frequent coastal flooding cause internal migration of population who are at risk of cholera, hepatitis, skin diseases and malnutrition. The GangesBrahmaputra delta is the most threatened area which has a very large human habitat facing effects of climate change in their health status, environment, living and employment. ${ }^{2}$ At present, a third of the world's population live within 60 kilometers of coastline and as many as 13 of the world's 20 largest cities are situated on the coastline. Any disruption in these places will force more than a billion people to migrate which will put strain on natural resources. ${ }^{1}$

Air pollution is directly related to environmental temperature and humidity. Climate change influences concentration of air pollutant in atmosphere. In addition, exhaust fumes from vehicles using fossil fuels contribute to respiratory illnesses like bronchial asthma and chronic obstructive pulmonary disease. Household energy use contributes to both air pollution and climate change with the use of solid fuel in cooking stoves. Studies indicate that about 1 million children die each year due to respiratory infections caused by this use of solid fuel in homes. 8

For a country like Bangladesh which depends on agriculture to feed its large population, changing climate can wreak havoc in food security. Salinization of arable land, flood, and drought can force people to leave their homes and settle elsewhere. This migration of people will lead to increased susceptibility to malnutrition and communicable diseases. Vector-borne diseases are likely to spread in this situation.

Health professionals can contribute to awareness building among the general population as they will be at the forefront of dealing with the fallout of climate change affecting health of the people. The World Health Organization has put forward a list of top 10 actions for health professionals which includes steps to be taken at global, local and personal level to meet the challenge of climate change. ${ }^{9}$ As the international community struggles to find a common ground in Copenhagen, it is the people of vulnerable countries who are facing the wrath of climate change. Measures for adaptation need to be in place in all future development plans and the involvement of health professionals in all these activities will benefit the entire nation as a whole. ${ }^{10}$

$15^{\text {th }}$ December, 2009

\section{Prof HAM Nazmul Ahasan}

\section{References}

1. Costello A, Abbas M, Allen A, et al. Managing the health effects of climate change. Lancet 2009; 373: 1693-733.

2. Rahman A. Climate change and its impact on health in Bangladesh. Regional Health Forum 2008;12:16-26.

3. Jay M, Marmot MG. Health and climate change. BMJ 2009;339:b3669.

4. McMichael AJ, Friel S, Nyong A. Global environmental change and health: impacts, inequalities, and the health sector. BMJ 2008;336:191-194

5. Nerlander L. Climate Change and Health. The Commission on Climate Change and Development; April 2009. Available at: www.ccdcommission.org Accessed on December 15, 2009

6. World Health Organization. How much excess disease can climate change cause? Available at: http://www.who.int/globalchange/faq/en/index.html Accessed on December 15, 2009

7. Reaz Ahmad. Farmers never say over in climate change war.The Daily Star 2009 December 6 Available at: http://www.thedailystar.net/ newDesign/news-details.php?nid=116597 Accessed on December 15, 2009.

8. Watts G. The health benefits of tackling climate change. Available at: http://download.thelancet.com/ flatcontentassets/series/health-and-climatechange.pdf Accessed on December 15, 2009.

9. World Health Organization. Protecting health from climate change top 10 actions for health professionals. WHO:2009.

10. Gill M, Stott R. Health professionals must act to tackle climate change. The Lancet 2009;374;1953 1955. 